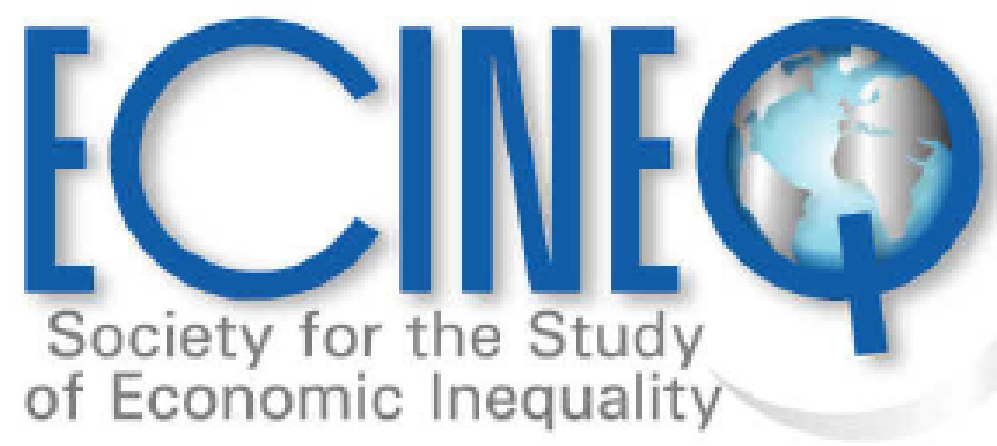

Working Paper Series

Multidimensional deprivation in heterogeneous rural areas: Spain after the economic crisis

Luis Ayala

Antonio Jurado

Jesús Pérez-Mayo 


\title{
ECINEQ 2020560
}

2020 September

www.ecineq.org

\section{Multidimensional deprivation in heterogeneous rural areas: Spain after the economic crisis}

\author{
Luis Ayala \\ UNED \\ Antonio Jurado \\ Universidad de Extremadura \\ Jesús Pérez-Mayo \\ Universidad de Extremadura
}

\begin{abstract}
We analyse the changes in multidimensional deprivation in very heterogeneous rural areas in Spain during the 2008 economic crisis using multigroup latent class models. Counterfactual distributions are implemented to identify the factors behind the change in deprivation in the different areas. We find that the economic crisis negatively affected direct indicators of the living standards in rural areas. A wide range of differences appears when specific rural areas are studied going beyond the usual dilemma between rural and urban areas. Our results also belie the common stereotype that the greatest incidence of monetary poverty in rural areas is offset by better living conditions.
\end{abstract}

Keyword: rural areas, multidimensional deprivation, latent class model, EU-SILC JEL Cassification: I32, R13 


\title{
Multidimensional deprivation in heterogeneous rural areas: Spain after the
} economic crisis

\author{
(draft version, the final paper will be published in a forthcoming issue of Regional \\ Studies) \\ Luis Ayala ${ }^{\mathrm{a}}$ \\ (Universidad Nacional de Educación a Distancia, EQUALITAS) \\ Antonio Jurado ${ }^{\mathrm{b}}$ \\ (Universidad de Extremadura) \\ Jesús Pérez-Mayo ${ }^{\mathrm{c}}$ \\ (Universidad de Extremadura)
}

\footnotetext{
${ }^{a}$ Facultad de Derecho, Universidad Nacional de Educación a Distancia, C/Obispo Trejo 2, 28040 Madrid, SPAIN, layala@,cee.uned.es

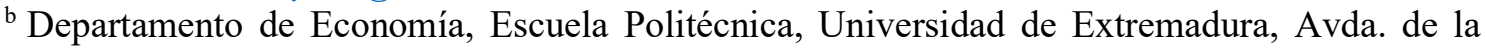
Universidad s/n, 10071 Cáceres, SPAIN, ajurado@unex.es

${ }^{\mathrm{c}}$ Departamento de Economía, Facultad de Ciencias Económicas y Empresariales, Universidad de Extremadura, Avda. de Elvas, s/n, 06071 Badajoz, SPAIN, jperez@unex.es
} 


\title{
Multidimensional deprivation in heterogeneous rural areas: Spain after the economic crisis
}

\begin{abstract}
We analyse the changes in multidimensional deprivation in very heterogeneous rural areas in Spain during the 2008 economic crisis using multigroup latent class models. Counterfactual distributions are implemented to identify the factors behind the change in deprivation in the different areas. We find that the economic crisis negatively affected direct indicators of the living standards in rural areas. A wide range of differences appears when specific rural areas are studied going beyond the usual dilemma between rural and urban areas. Our results also belie the common stereotype that the greatest incidence of monetary poverty in rural areas is offset by better living conditions.
\end{abstract}

Keywords: rural areas, multidimensional deprivation, latent class model, EU-SILC.

JEL: I32, R13 


\section{INTRODUCTION $^{1}$}

Among the variety of elements that influence the development and profiles of multidimensional deprivation, the spatial dimension has received less attention than other determining factors. This is especially noticeable in the case of rural areas, where the evidence on multidimensional deprivation -understood as the proportion of households whose living conditions are below what is considered to be socially acceptable- is scarce. This relatively marginal consideration is due to several reasons. First, in most highincome countries the contribution of the primary sector to the GDP and employment has continued to decrease. Second, depopulation and ageing in these areas have limited the analysis of living conditions to the issues of the adequacy of social benefits and access to basic public services.

There are also methodological problems and a limited availability of data to measure deprivation in rural areas. The definition of appropriate thresholds for sparsely populated areas remains a challenge for applied research. The difficulties of adapting the usual methodological decisions to more disaggregated territorial areas add to the heterogeneity of rural areas themselves, due to both the diversity of patterns of productive specialization and differences in the socio-demographic structure. Given the lack of availability of sufficiently disaggregated data, overly simplistic classifications are often used.

The higher occurrence of income poverty in rural areas is often opposed to the hypothesis that situations of multidimensional deprivation are, on the contrary, lower in these areas where the effects of recessionary economic cycles also tend to be less adverse. Drawing

\footnotetext{
${ }^{1}$ Draft version. The final paper will be published in a forthcoming issue of Regional Studies.
} 
on the literature on multiple deprivation, this paper aims to provide an answer to three questions: Is multidimensional deprivation less sensitive to recessions in rural than urban areas? Was the impact of the 2008 economic downturn different across heterogeneous rural areas in terms of multidimensional deprivation? Is an individual with certain characteristics more likely to experience deprivation depending on the area where she/he resides? To answer these questions, we analyse the changes in multidimensional deprivation in Spanish rural areas before and at the height of the 2008 economic crisis. Spain is a country with a broad heterogeneity in rural areas, and it was one of the OECD countries where the effects of the economic crisis were most adverse. It is also a country with very large territorial differences in access to essential public services (HerreroAlcalde and Tranchez-Martín, 2017).

The paper contributes to the previous literature in mainly two ways. First, we solve the problem of measuring multidimensional deprivation in disaggregated areas using an extended version of a latent class model. These models can partially solve the problem of measurement error usually serious in most of the approaches. Although our approach is not new, we apply it to an issue to which it has not been applied before getting insights that are new to the topic. Second, decomposition analyses of material deprivation are conducted by estimating counterfactuals to identify the major factors behind the change in deprivation by areas.

Our results show that in most rural areas, excepting large holdings, there is a lower incidence of the different types of multidimensional deprivation than in urban areas. However, it increased in most rural areas because of the economic crisis. Such a result 
challenges the stereotype of rural areas as a means of protection against multidimensional deprivation.

The paper is structured as follows. Section 1 is a brief overview of the issue. Second, the data used in the study and the demarcation criteria of the habitats are presented. Third, the latent class method used to measure multidimensional deprivation is introduced. Fourth, a detailed analysis of deprivation during the crisis period is performed. The study ends with a brief summary of conclusions.

\section{LITERATURE REVIEW}

The past decade has witnessed an intense debate over the best procedures for the measurement of poverty. A rapidly expanding literature has focused on the notion of multidimensional deprivation. By aggregating different dimensions of material wellbeing into a single index it is possible to have a more expansive view of households' wellbeing than the one shown by monetary poverty. Such a definition incorporates an idea of poverty more related to each person's or household's standard of living, expressing their inability to afford some items considered by most people to be desirable or even necessary to lead an adequate life.

The use of these indices is especially relevant for assessing welfare differences in territorial areas. The experiences of urban and rural areas are usually contrasted under the stereotype that in the former there are less poverty and deprivation but greater sensitivity to economic downturns. In practice, rural areas are far from immune to economic downturns in terms of living conditions. Some authors have stressed that availability of 
services and jobs, together with tranquility, space and lower levels of criminality, result in a high quality of life for rural dwellers (Leeuwen, 2010). However, although urban areas tend to be more exposed to some of the adverse macroeconomic conditions, rural areas are not exempt from significant risks regarding households' vulnerability. For most countries, information on the differences between urban and rural areas in monetary poverty rates is actually available, and it clearly points to an increased incidence in rural areas. Available evidence from the United States shows a deterioration of poverty over time in rural areas compared to urban areas (Ulimwengu and Kraybill, 2004), in terms of both income and assets (Fisher and Weber, 2005). Comparable data from the EU Survey of Living Conditions systematically reflect lower poverty rates in urban than in rural areas in EU countries (European Commission, 2008).

The highest incidence of monetary poverty and its persistence over time in rural areas introduces numerous issues for both research and decision-making. Some studies show that, even when the effects of a large number of individual variables and of the local environment are controlled, non-observable characteristics in rural areas increase local poverty rates and the individual likelihoods of being poor (Weber et al., 2005). There may be spatial traps of poverty, resulting from a low endowment of "geographic capital" -physical, social, and human capital-, making the environment a determining impact factor (place matters) (Bird et al., 2002). This spatial trap determines both a higher incidence of poverty and the fact that national policies that seek to reduce its incidence are significantly less effective (Weber et al., 2004; Simmons et al., 2007; Mammen et al., 2011). 
The greater incidence of poverty in rural areas is confirmed and often opposed to the hypothesis that situations of material deprivation are, on the contrary, lower in these areas. Although some studies such as analyses of food deserts have indirectly addressed the issue, the implementation of new approaches to multidimensional deprivation in the study of rural areas has been very limited. Mosley and Miller (2004) found that, for the US case, indicators were worse in large cities and non-urban areas. In the case of Spain, Jurado and Pérez-Mayo (2008) defined various categories of habitat to find some differences in poverty and deprivation rates between urban and rural areas. These differences were primarily rooted in the growing dependence on social transfers in rural areas.

This limited evidence makes it difficult to predict to what extent rural areas may suffer less from the problem of multidimensional deprivation during recessions. Some authors have found that the Great Recession - usually characterized as a global crisis- had also a significant impact at the local level. The explicit geographies of the subprime crisis have been explored in different countries (Martin, 2011). The evidence suggests that the rural housing market experienced a deeper crisis than its urban counterpart (Murphy and Scott, 2014).

In any case, the possible effects of recessions on multidimensional deprivation in rural areas are closely related to the demographic and economic characteristics of each area, and to a variety of institutional factors that may or not provide protection against adverse macroeconomic shocks. In this sense, some authors stress the role of place resilience to cope with economic crises and reducing the vulnerability of these areas to economic uncertainty (Glover, 2012; Wilson, 2012). Giannakis and Bruggeman (2017) identified the positive effect of accessibility and the negative effect of a large manufacturing sector 
in the ability of regions to withstand recessionary shocks, while education and economic development positively affected the resilience of both large and small regional European economies. Also looking at the asymmetric spatial effects of the crisis, Capello et al. (2015) found that the quality of the activities and of the production factors hosted, the density of external linkages and cooperation networks, and the quality of urban infrastructure, are all factors giving greater economic resilience to cities and to the regions that host them. Therefore, regions hosting strong, large, and dynamic cities might be more resilient to adverse external shocks with respect to rural ones. Healy and Bristow (2018) also found that places identified as innovation leaders at the time of the crisis were significantly more likely to have either resisted the crisis or recovered quickly from it.

According to this evidence, it is not clear whether a lower incidence of economic crises in rural areas should be expected. While there are several avenues through which economic downturns can potentially affect urban areas to a higher extent -unemployment or wage reductions-, in rural areas the weather, commodity markets, health and safety issues, can increase chronic stress, with a significant and lasting impact on individual well-being and family ties (Salamon et al., 1998). These factors are added to those usual in recessions, such as the deterioration of the labour market -less important in aging rural areas- or the reduction in public investment.

We must also add that interdependency between rural and urban areas is growing. Urban and rural areas are getting more interwoven, physically, financially, functionally, and culturally (Leeuwen and Nijkamp, 2010). As stressed by Torre (2015), rural areas are under an increasingly strong influence of cities and urban population, and where rural growth occurs it is due to the expansion of nearby cities or more long-distance urban 
demand for rural products. In terms of the complexity of patterns, variables and interactions, the possibility of an absolute dichotomy between the urban and the rural seems disqualified; a number of different representations reinforce the two as defining poles, but include a continuum (De Souza, 2018).

Despite the growing interdependence, remarkable differences exist between rural and urban areas. First, as will be seen in the next section, the levels of income, employment and demographic characteristics of the population remain very different. Second, rural areas are not, however, a homogenous reality. The differences in the demographic characteristics of the population, in the density of external linkages or in the cultural framework that favours greater resilience, mean that a possible macroeconomic shock can affect each rural area differently. For a robust estimate of the impact of the crisis on multidimensional deprivation in rural areas, it is therefore necessary to have both a sufficiently disaggregated classification of rural areas and a method for evaluating these effects.

DATA

Data on living conditions

The data we use in this analysis have been drawn from the Spanish sample (ECV) of the European Union Statistics on Income and Living Conditions (EU-SILC). This dataset was established by Eurostat in 2004 and is the main source for studies on multidimensional deprivation in EU countries. In this study, the ECV is used for the years 2005 and 2012. This was the period of deepest economic recession, with a national unemployment rate 
that rose from $8.4 \%$ in the third quarter of 2005 to over $26 \%$ by the end of 2012 . The individual is used as the unit of analysis, and the samples include 36,678 and 33,573 observations for 2005 and 2012, respectively. ${ }^{i}$ The data come from specific information produced for this study by the National Institute of Statistics (INE), which for the first time includes differentiation of heterogenous rural areas, allowing a much more precise analysis of their living conditions. ${ }^{\text {ii }}$

The structure and design of the survey make it possible to collect very detailed information on income, living conditions, and certain demographic and material characteristics of households. Thus, it is possible to estimate multidimensional deprivation indicators from the information on material well-being provided by the survey.

\section{Definition of rural areas}

The territorial analysis of deprivation requires the definition of what areas are considered urban and rural. To answer the question of what constitutes the rural or the non-urban is that a final definition is hard to come by, since the definition of rural is not limited in a static, traditional conduct (De Souza, 2018). According to Frey and Zimmer (2001), three elements should be considered to define rural areas: ecological-population and density-, economic-function of an area and activities that take place-, and social character, much harder to measure. In practice, several studies use the OECD (1994) classification as a criterion, which is mainly based on population density and which considers localities with a density of less than 150 inhabitants per $\mathrm{km}^{2}$ to be rural areas. Using this information, the Spanish provinces (NUTS3) can be grouped into three clusters depending on their 
population densities. However, given the wide area of the municipal boundaries and the population distribution in Spain, many cities would be classified as predominantly rural areas.

The ECV includes a variable combining total population and population density with three possible categories: densely populated areas, semi-urban or intermediate areas, and sparsely populated areas. Although this classification has the clear advantage of being directly available in the dataset, it does not avoid some of the problems of the previous classification. As an alternative, some studies use classifications considering the municipal population. Jurado and Pérez-Mayo (2008) divided the municipalities into four clusters only depending on the number of inhabitants. However, a purely populationbased criterion makes this classification insufficient for the study of heterogeneous rural areas. As suggested by Goerlich and Cantarino (2015), one possible advance would be using specific thresholds of densities and sizes of urban agglomerations regardless of the official classification of administrative units.

The classification we use in this paper follows the criteria proposed by Pereira et al. (2004), that do not only include the size and density of the population but also the productive specialization of the various rural areas, and orography. The variables used were population density, intensive production uses and percentage of irrigation on agricultural land, average altitude, average land slope, number of population centres by municipalities, type of agricultural production, and average size of farms.

Initially, these authors used a classification with eight groups. However, we checked that three of them were very small and similar in their general characteristics to other existing 
ones. For this reason, we have grouped the territories into five types ${ }^{\mathrm{iii}}$, always using the parameters and thresholds defined by Pereira et al. (2004): ${ }^{\text {iv }}$

1) Urban areas: more than 160 inhabitants per $\mathrm{km}^{2}$ or more than 500,000 inhabitants.

2) Intermediate areas: between 80 and 160 people per $\mathrm{km}^{2}$ or more than $10 \%$ of the utilized agricultural area under irrigation.

3) Arable crops and permanent pastures smallholdings

- Arable crops and agricultural smallholdings: over $40 \%$ of utilized agricultural area is devoted to cereal and holdings with more than 200 hectares account less than $50 \%$ of the agricultural land;

- Permanent pastures (including meadows) and agricultural smallholdings: over $40 \%$ of utilized agricultural area is devoted to grazing and holdings with more than 200 hectares account less than $50 \%$ of the agricultural land;

- Scattered rural communities: areas with 30 or more small villages.

4) Arable crops and permanent pastures large holdings

- Arable crops and agricultural large holdings: over $40 \%$ of utilized agricultural area is devoted to cereal and holdings with more than 200 hectares accounts $50 \%$ or more of the agricultural land; 
- Permanent pastures and agricultural large holdings: over 40\% of utilized agricultural area is devoted to grazing and holdings with more than 200 hectares account $50 \%$ or more of the agricultural land.

5) Mountain areas: areas with more than $50 \%$ of their land area above 1,000 metres or with more than $48 \%$ of their land with a slope greater than $3 \%$.

A detailed description of the main variables and characteristics of the areas can be found in Pereira et al. (2004). ${ }^{\mathrm{v}}$ This classification considers a greater heterogeneity of areas than that used in previous studies (326 areas, with data from more than 8,000 municipalities). The results presented from now on may differ therefore from those that would result with other definitions of rural areas. The percentages of the total population in 2012 were: urban areas $(69.2 \%)$, intermediate areas $(15.6 \%)$, arable crops and permanent pastures smallholdings (5.7\%), arable crops and permanent pastures large holdings (5.9\%), and mountain areas $(3.7 \%)$. These percentages remained practically unchanged during the period under study. ${ }^{\mathrm{vi}}$

Tables A1 y A2 in Annex I show the different characteristics of the population living in the corresponding areas. In all rural areas income is lower on average than in urban areas. The differences in income between the rural areas also stand out. Income in mountain areas -the rural area where it is highest- is $25 \%$ higher than in large holdings. These differences are closely related to the extent of unemployment.The differences are wide, and it is in large holdings where unemployment rates are higher, while the opposite occurs in mountain areas. It should be noted that unemployment -with the exception of intermediate areas-grew more in urban areas, as is often the case in economic downturns. 
In general, unemployment grew more where rates were lower. Table A2 shows the differences by areas in demographic characteristics. In general, except in the smaller population categories -where the representativeness is lower-, there are no major significant changes in the demographic profiles of each area allowing comparisons between the two years. ${ }^{\text {vii }}$

Heterogeneity in living conditions in these areas can be also verified by checking whether situations of income poverty differ from one another. Poverty is estimated as the percentage of the population with an equivalent income below $60 \%$ of the median. As it can be observed in Table 1 , almost $20 \%$ of the population had income less than $60 \%$ of the national median in 2005 . The rate significantly increased to $21.3 \%$ in 2012 . This increase was not equally distributed among the different areas, standing out the difference between urban and rural areas. Before the economic crisis, the rates in urban areas were more than $13 \%$ lower than the national average, in stark contrast to each rural area defined. In some areas, such as large holdings, the rates were nearly $60 \%$ higher than the average. However, these differences narrowed with the prolonged economic crisis, though the best relative situation of urban areas remained.

\section{[TABLE 1]}

Table 1 also illustrates the wide range of variation among rural areas. In 2005, the highest poverty rates were those of large holdings. During the crisis, the rates significantly decreased in smallholdings, and more moderately in large holdings and in mountain areas, though they increased in intermediate areas and particularly in urban areas. The issues of job losses and falling wage income were particularly concentrated in the latter, whereas 
in most rural areas incomes remained stable due to the maintenance of the purchasing power of pensions.

\section{A LATENT CLASS MODEL FOR MULTIDIMENSIONAL DEPRIVATION IN HETEROGENEOUS AREAS}

Latent class model

The notion of multidimensional deprivation refers to the inability of households to afford some items considered by most people to be necessary to have an adequate life. The literature provides a wide range of possibilities to build a synthetic index of multiple deprivation from the counting approach to other where multidimensional statistical techniques are applied. These methodological options are related to the selection and weighting of the partial indicators of deprivation -uniform, frequency-depending or declared relevance in some surveys.

The methodological approach followed here belongs to the group of latent variable models. Since the information is contained in some observable metric indicators and identifying groups in the population defined as categories of an unobservable variable for deprivation is sought, the latent class model is the most adequate.

In brief, since this model is well known, ${ }^{\text {viii }}$ an $x_{q}$ latent variable with a total of $J$ classes representing multidimensional deprivation is estimated from a set of $p$ partial indicators of deprivation $\left(x_{1}, \ldots, x_{p}\right)$, with a number of categories $I_{1, \ldots}, I_{p}$ by the following equation: 


$$
\pi_{i_{1} \ldots i_{p}}=\sum_{j=1}^{J} \pi_{i_{1} \ldots i_{p} j}
$$

where

$$
\pi_{i_{1} \ldots i_{p j}}=\pi_{j} \pi_{i_{1} \ldots i_{p} \mid j}=\pi_{j} \pi_{i_{1} \mid j} \ldots \pi_{i_{p} \mid j}
$$

and $\pi_{i_{1} \ldots i_{p j}}$ represents the likelihood of the joint distribution $\left(x_{1}, \ldots, x_{p} ; x_{q}\right)$. Moreover, $\pi_{j}$ is the probablity of belonging to the $j$ latent class, and $\pi_{i_{1} \ldots i_{p} \mid j}$ is the probability of having a specific response pattern given that $x_{q}=j$.

After the joint and conditional probabilities have been estimated, the class sizes are computed by using the Bayes theorem. Finally, each observation is assigned to the most likely latent cluster given its response patterns (the modal conditional probability).

Since the discussion of the actual role of the spatial dimension in deprivation analysis is the goal of this paper, the multi-group latent class models or simultaneous latent-class analyses across groups is tested (Kankaras and Vermunt, 2014). ${ }^{\text {ix }}$ They extend the expression [1] to datasets where a covariate divides them into some clusters. These models lie on the existence of measurement equivalence across groups. Such assumption is related to the level of by-group similarity of response patterns given the latent class membership. Figure 1 helps to understand the alternative models that can be found depending on the influence of spatial areas in latent and response probabilities.

[FIGURE 1] 
Naming A the variable representing the spatial areas, $D$ the latent variable that provides the estimated level of deprivation, and $I$ the set of observed variables or indicators, Figure 1(a) shows the complete homogenous model because there is no link between $A$ and $D$ or I. This absence of links means that the response and latent probabilities are independent of the area the individuals belong to. Therefore, comparison between groups is impossible and non-required because neither response patterns nor latent probabilities depend on the spatial areas where the individuals live. The opposite case presented in Figure 1(c) is the unrestricted structural latent class model which assumes full heterogeneity by allowing all the parameters to be different across groups. Since all the model's parameters are group-specific, group comparability is very difficult.

Comparing the latent classes across groups involves imposing across-groups restrictions on the model parameters (Figure $1 \mathrm{~b}$ ). This constraint involves that the conditional response probabilities are equal across groups -in our case, response patterns are the same in each area. However, sometimes only some of the parameters are restricted to be equal.

Application of the latent class model to the ECV

The indicators used to estimate deprivation are related to living conditions - the inability to pay unexpected expenses, to afford a one-week annual holiday, a meal with meat, chicken, fish or vegetarian equivalent every second day, not having a car or computer, and being confronted with payment arrears- together with deficiencies in housing conditions, such as trouble keeping the adequate heating of a dwelling in winter. ${ }^{\mathrm{x}}$ They are part of the set of items used by both Eurostat and INE in their indicators of severe material deprivation and material deprivation, respectively. We include two other 
indicators already used by other authors (Martínez and Navarro, 2015): housing-cost overburden and overcrowding, potentially relevant for Spain. ${ }^{\mathrm{xi}}$

\section{[TABLE 2]}

Then, it was necessary to select a model. The choice of the best model determines the number of classes of the latent variable (multiple deprivation) that can be identified in the population. The results in Table 2 show that the most appropriate model is that which identifies three population groups according to their level of deprivation. According to the $\mathrm{L}^{2}$ statistic, the hypothesis of independence -the results confirm that there are latent groups in the population- and the remaining estimated models should be rejected. ${ }^{\text {xii }}$ To find the best model, additional criteria as BIC, increased likelihood, and classification error (E) are used. The two-points improvement in the likelihood when using the fourclass instead of the three-class model $-87 \%$ vs. $85 \%$ - contrasts with the increased classification error, which rises from $14 \%$ to $20 \%$. As a result, the latter was chosen so that the selected model is that which involves three different underlying groups in the population due to the increase in explaining the actual deprivation. Deprivation is not assumed as a binary phenomenon. It seems reasonable to consider an intermediate group of individuals who show deprivation in some indicators but who do not belong to extreme categories. As a result, there would be three groups in the population: non-deprived, in moderate deprivation and in severe deprivation. The former does not suffer any type of deprivation and the latter accumulate several deficiencies in the items described previously.

[TABLE 3] 
The same methodological options were applied to data for the year 2012. ${ }^{\text {xiii }}$ Again, the results (Table 3) show that the three-class model is preferred due to the balance between improvement in explanatory power and classification error.

\section{MULTIDIMENSIONAL DEPRIVATION IN RURAL AREAS}

Changes in deprivation in rural areas

Before the crisis, a small group of the population (5.3\%) showed a severe degree of deprivation, whereas more than half of the individuals could be described as non-deprived (Table 4). The remaining population can be identified as in a situation of moderate deprivation after the analysis of conditional profiles -the probability of experiencing deprivation in an indicator, given a group of deprivation. This intermediate group can be defined as a vulnerable group that can meet basic needs, though there is a risk of deprivation in some goods or activities.

[TABLE 4]

In terms of the urban-rural dichotomy, deprivation was in general less relevant in urban areas, though this was not the case in mountain areas and smallholdings. The fact that severe material deprivation was greater than in urban areas only in areas where large holdings predominate also stands out. Therefore, the situation before the crisis was characterized by a slightly higher incidence of deprivation in rural areas but, in general, with a lower intensity than in urban areas. 
Another striking feature from the comparison of the different geographical areas is the diversity of results in rural areas, with indicators of severe material deprivation in large holdings higher than in smallholdings and mountain areas. Both findings reinforce the idea of the singularity of rural areas in the assessment of living conditions and of a marked heterogeneity among the different areas. ${ }^{\text {xiv }}$ In general, the incidence of severe deprivation was higher where there were also high unemployment rates, as in large holdings -with lower average income-, and intermediate rural areas -although they seem to benefit from the proximity to more important development axes from which they receive indirect opportunities-, with similar results throughout the analysis to those in urban areas. One of the differential characteristics of large holdings is the greater presence of seasonal immigrant workers, whose living conditions are clearly worse than those of other residents in this area.

In contrast, severe deprivation was much lower in smallholdings and mountain areas. In the former, characterized by higher levels of population aging, with greater savings therefore in housing and leisure expenses, old-age benefits -although low- seem to have a greater effect on the ability to ensure basic levels of material well-being than in large holdings. The latter are areas with significant landscape resources and a growing tourist attraction, which have meant that - unlike most rural areas- they have attracted a certain percentage of the population. In general terms, there are greater difficulties in terms of poverty and multiple deprivation in cereal areas, more dependent on agricultural activity than other areas where the possibilities for diversification of activity are greater. 
The severity of the economic crisis in Spain, with a dramatic growth in the unemployment rate to greater than $25 \%$, caused a rapid growth in the incidence of monetary poverty. It went from a rate below $20 \%$ in 2005 to $22.2 \%$ in 2012 , despite the continued lowering of the threshold due to a reduction in the median income. As shown before, this growing relative poverty affected rural areas to a lesser extent, except in a few cases in which the opposite evolution occurred. Therefore, it seems appropriate to analyse whether a similar process occurred in the case of multidimensional deprivation.

The results in Table 4 for 2012 show an important change in the incidence of deprivation in the entire country. Although the percentage of non-deprived individuals remained stable during the crisis, there was a marked change in the deprivation profiles. Severe deprivation situations gained weight and affected $10 \%$ of the population, almost double that in the pre-crisis situation at the expense of a reduction in moderate deprivation.

Unlike what was observed in the case of monetary poverty, material deprivation (moderate plus severe) slightly decreased in all rural areas except for intermediate areas. However, a significant increase also occurred in the most severe forms of deprivation, particularly in smallholdings and mountain areas, where this type of deprivation was lowest before the crisis. It seems that some of the advantages discussed above lost intensity with the change in the economic cycle. Some rural areas, typically regarded as a haven against changes in macroeconomic conditions, may have been less resistant to the effects of the economic downturn in terms of living conditions than in terms of insufficient household income. In general, except for mountain areas, deprivation grew less where the rise in unemployment was lower. 
Another important issue in the assessment of deprivation trends is whether the crisis extended or reduced its spatial nature. Tables $5 \mathrm{a}$ and $5 \mathrm{~b}$ report the results of estimating the different structural latent class models before and after the crisis. Leaving aside the full homogeneous model -no relationship between spatial areas and latent classes and response patterns- the statistics are very similar and the increase in explaining power of the structural homogeneous stands out. Therefore, the influence of spatial areas on deprivation can be accepted in the two years considered. Living in a specific area affects the relative risk of being deprived.

[TABLE 5.a]

[TABLE 5.b]

Decomposition of the change in multidimensional deprivation in each area

The spatial variations observed in the extent and structure of deprivation between the two years considered may be double-caused. First, the Great Recession could increase the incidence of some indicators because meeting the households' needs is harder. Table A3 shows that the growth of some partial deprivation indicators was higher in some rural areas than in others. Second, the results might be criticised because deprivation might have changed because so has the population, without any significance therefore for the spatial dimension. Even if the same households had been surveyed in both years, their socioeconomic characteristics could have changed.

To address this issue, the decomposition of poverty rates proposed by Ayala et al. (2011) is applied. Although this methodology is not new we apply it to an issue to which it has 
not been applied before, getting insights that are new to the topic. Rural-urban disparities of poverty or deprivation may be analysed in detail using this approach. This procedure starts from some logit models for the deprivation risk in each area before and after the crisis. ${ }^{\mathrm{xv}}$ Both are assumed to depend on some individual and household characteristics: household head's age, gender, educational attainment and labour status, household size, low work intensity in the household, household type and individual age. If deprivation rates are defined as average probabilities, differences between 2005 and 2012 can be split into differences due to changes in population composition and differences due to changes in the relative risk of each covariate:

$$
\hat{p}^{12}-\hat{p}^{05}=\overline{\overline{F\left(X^{12^{\prime}} \beta^{12}\right)}}-\overline{\overline{F\left(X^{05^{\prime}} \beta^{05}\right)}}
$$

Table 6 reports a picture where deprivation increased during the crisis in all areas. The possible changes in the population between periods, mainly those related to the labour market due to the Great Recession, have a very limited influence on the observed changes in deprivation. The same personal and family characteristics were more important for the risk of deprivation in 2012 than in 2005.

[TABLE 6]

However, both the aggregate data and the one corresponding to urban areas yield a very relevant result. In rural areas this increase in the relative risks is much greater to the extent that, given the evolution of social and demographic characteristics, deprivation was 
expected to decrease -negative values in the second column of table 6 . The greatest increase in deprivation is observed in large holdings and mountain areas.

Again, there is a need to consider the spatial dimension when dealing with this issue. In other words, it is necessary to tackle the impact of certain factors such as ageing, lower level of education or the deterioration of the labour market in rural areas on the living conditions of people living in these areas. The same characteristics produce very different results and it is not easy for people living in these areas to find successful resilience strategies. Their set of life chances is more constrained and labour and economic activity is progressively concentrated in urban areas -and even, the public sector investments, making educated or more innovative people migrate to urban areas looking for a better return on their skills.

\section{CONCLUSION}

The changes in rural areas in recent decades have affected the income and living conditions of household residents in these habitats. This evolution, marked by the gradual ageing of the population and its exodus to cities, has led to very heterogeneous situations in rural areas. This variety barely corresponds to the assumed uniformity from which this reality is typically considered.

In this paper we have analysed the heterogeneity in situations of multidimensional deprivation in various types of habitats and the effects of the crisis in each area. The wealth of information shows that there are notable differences in the extent of these issues both between urban and rural areas and within the latter. 
Unlike what some studies on monetary poverty show, it appears that there is a lower incidence of severe material deprivation in certain rural areas, though there is a wide variety of experiences, which makes it difficult to talk about common results. Severe deprivation is higher in urban areas, except for large holdings. In general, before the economic crisis began severe deprivation was higher in the areas with higher unemployment rates and lower in areas where the importance of public pensions was greater.

However, one of our research findings is the importance of some intrinsic characteristics of each rural area to explain social well-being and multidimensional deprivation. That is the case of the potential advantages of intermediate rural areas to benefit from the proximity to more important development axes, the greater presence of seasonal immigrant workers with worse living conditions in large holdings, the higher contribution of social benefits in smallholdings, or the opportunities brought about by landscape resources in mountain areas. Although the possible effects on multidimensional deprivation of changes in the economic cycle in these areas are closely related to their demographic and economic characteristics, this diversity of specific factors makes the possible responses to the crisis different in each area. In addition to this heterogeneity, due to economic, cultural, and social differences, the role of place resilience to cope with economic crises is also different across areas. This diversity should be considered when developing and designing public initiatives that take into account the multidimensionality of deprivation. 
Both the estimation of various types of deprivation indicators and the decomposition of their changes make it possible to affirm that the crisis had a particularly significant impact on some of these areas. Severe deprivation has increased in almost all rural areas, though the relative improvement in household income -due to the greater stability of social security transfers- has reduced the incidence of monetary poverty. In any case, rural areas have not been spared from the impact suffered by most of the population. More difficulties added to those already occurring before the sharp slowdown in economic activity.

In general terms, deprivation grew less where the rise in unemployment was lower. Another relevant result is that a significant increase occurred in the most severe forms of deprivation in small holdings and mountain areas, the areas where the levels of this type of deprivation were the lowest before the crisis. As aforementioned, it seems that some of the advantages discussed above lost intensity with the crisis. As a result, some rural areas, which are typically regarded as a shield against changes in macroeconomic conditions, may have been less resistant to the effects of the economic downturn in terms of living conditions than in terms of insufficient household income.

A final finding provided by the decompositions performed is the confirmation of the idea that place matters. The same socioeconomic characteristics can have very different effects on the probability of deprivation in rural and urban areas. As stated in the paper, there may be spatial traps of deprivation, resulting from a low endowment of geographic capital that makes the environment a determining impact factor. 
In short, the economic crisis has negatively affected direct indicators of the living standards in rural areas. Moreover, the observed results belie the common stereotype that the greatest incidence of monetary poverty in rural areas is offset by better living conditions. These findings assist in formulating policies and outreach efforts that may increase social well-being in rural areas. To be effective, the necessary reduction of the problems of multidimensional deprivation should address the marked heterogeneity of the effects by types of rural areas, which makes it necessary to consider the complexity of each area and the diversity of the demographic and economic structures of each environment.

While we should expect that the crisis could have had a greater incidence in rural areas, affecting the levels of economic vulnerability and the living conditions of households, these areas are not, however, a homogenous reality. The differences in the demographic characteristics of the population, in the density of external linkages or in the cultural framework that favours greater resilience, mean that a possible macroeconomic shock can affect each rural area differently. These results for Spain could also be relevant for other countries that face similar processes of population aging in rural areas and where there is no single rural reality, but different rural areas with different characteristics and problems.

\section{ACKNOWLEDGMENTS}

Luis Ayala gratefully acknowledges funding from the Community of Madrid (H2019/HUM-5793) and from the Spanish Ministry of Economy, Industry, and Competitiveness (ECO2016-76506-C4-3-R). Antonio Jurado and Jesús Pérez-Mayo gratefully acknowledge funding from the Junta of Extremadura and the ERDF Funds (GR15023). 


\section{REFERENCES}

Ayala, L., Jurado, A., and Perez-Mayo, J. (2011): "Income Poverty and Multidimensional Deprivation: Lessons from Cross-regional Analysis". Review of Income and Wealth 57, 4060 .

Bird, K., Hulme, D., Moore, K. y Shepherd, A. (2002): "Chronic poverty and remote rural areas", CPRC Working Paper $n^{\circ} 13$.

Capello, R., Caragliuy, A. and Fratesi, U. (2015): "Spatial heterogeneity in the costs of the economic crisis in Europe: are cities sources of regional resilience?". Journal of Economic Geography 15, 1-22

De Souza, P. (2018): The Rural and Peripheral in Regional Development: An Alternative Perspective. Oxon: Routledge.

European Commission (2008): Poverty and social exclusion in rural areas. Directorate-General for Employment, Social Affairs and Equal Opportunities, European Communities.

Fisher, M. G. and Weber, B. A. (2005): "Does Economic Vulnerability Depend upon Place of Residence? Asset Poverty across Metropolitan and Nonmetropolitan Areas." Review of Regional Studies 34, 137-155.

Frey, W.H. and Zimmer, Z. (2001): "Defining the City". In Paddison, R. (ed.): Handbook of Urban Studies. London: SAGE Publications.

Giannakis, E. and Bruggeman, A. (2017): "Determinants of regional resilience to economic crisis: a European perspective". European Planning Studies 25, 1394-1415.

Goerlich, F.J. and Cantarino, I. (2015): "Estimaciones de la población rural y urbana a nivel municipal". Estadística Española 57, 5-28.

Glover, J. (2012): "Rural resilience through continued learning and innovation". Local Economy 27, 355-372.

Healy, A. and Bristow, G. (2018): "Innovation and regional economic resilience: an exploratory analysis". The Annals of Regional Science 60, 265-284.

Herrero-Alcalde, A. and Tranchez-Martín, M. (2017): "Demographic, political, institutional and financial determinants of regional social expenditure: the case of Spain". Regional Studies 51, 920-932.

Jurado, A. and Pérez-Mayo, J. (2008): "Pobreza y territorio". In Ayala, L. (ed.): Desigualdad, pobreza y privación. Madrid: Fundación FOESSA.

Kankaraš M., Vermunt J.K. (2014) Simultaneous Latent-Class Analysis Across Groups. In: Michalos A.C. (eds) Encyclopedia of Quality of Life and Well-Being Research. Springer, Dordrecht

Leeuwen, E.S. (2010): Urban-Rural Interactions: Towns as Focus Points in Rural Development. Heidelberg: Springer.

Leeuwen, E.S. and Nijkamp, P. (2006): "The Urban-rural Nexus". Studies in Regional Science $36,283-303$.

Mammen, S., Lawrence, F.C., St. Marie, P., Berry, A.A., and Knight, S.E. (2011): "The Earned Income Tax Credit and Rural Families: Differences Between Non-participants and Participants". Journal of Family and Economic Issues 32, 461-472.

Martin, R. (2011): "The local geographies of the financial crisis: from the housing bubble to economic recession and beyond". Journal of Economic Geography 11, 587-618.

Martínez, R. and Navarro, C. (2015): "Pobreza y privación: tendencias y determinantes". Documento de Trabajo, Fundación FOESSA.

Mosley, J. and Miller, K.K. (2004): "Material Hardship Across Place". Institute of Public Policy, Harry S. Truman School of Public Affairs, University of Missouri-Columbia.

Murphy, E. and Scott, M. (2014): "Household vulnerability in rural areas: Results of an index applied during a housing crash, economic crisis and under austerity conditions". Geoforum 51, 75-86.

OECD (1994): Creating rural indicators for shaping territorial policies. Paris: OECD. 
Pereira, D., Fernández-Such, F., Ocón, B. and Márquez, O. (2004): Las zonas rurales en España: un diagnóstico desde la perspectiva de las desigualdades territoriales y los cambios sociales y económicos. Madrid: Fundación FOESSA.

Pérez-Mayo, J. (2005): "Identifying deprivation profiles in Spain: a new approach". Applied Economics 37, 943-955.

Salamon, S., Farnsworth, R.L. and Bullock, D.G. (1998): "Family, community and sustainability in agriculture". In D'Souza, G.E. and Gebremedhin, T.G. (eds.): Sustainability in Agricultural and Rural Development. Dartmouth Pub Co.

Simmons, L.A., Dolan, E.M. and Braun, B. (2007): "Rhetoric and Reality of Economic Selfsufficiency Among Rural, Low-Income Mothers: A Longitudinal Study". Journal of Family and Economic Issues 28, 489-505.

Torre, A. (2015): "New Challenges for Rural Areas in a Fast Moving Environment". European Planning Studies 23, 641-649.

Ulimwengu, J. M. and Kraybill, D.S. (2004): "Poverty over Time and Location: An Examination of Metro-Nonmetro Differences." American Journal of Agricultural Economics 86, 1282 1288.

Weber, B, Edwards, M. and Duncan, G. (2004): "Single mother work and poverty under welfare reform: are policy impacts different in rural areas?". Eastern Economic Journal 2004, 3151 .

Weber, B., Jensen, L., Miller, K., Mosley, J. and Fisher, M. (2005): “A Critical Review of Rural Poverty Literature: Is There Truly a Rural Effect?”. International Regional Science Review 28, 381-414.

Wilson, G.A. (2012): Community Resilience and Environmental Transitions. London: Routledge. 
Table 1 . Poverty rates by types of area

\begin{tabular}{lcc} 
& \multicolumn{2}{c}{ Poverty rate } \\
Areas & 2005 & 2012 \\
\hline Urban areas & $17.3^{*}$ & $19.6^{*}$ \\
Intermediate areas & 23.0 & 24.7 \\
Arable crops and permanent pastures smallholdings & $26.6^{*}$ & $22.1^{*}$ \\
Arable crops and permanent pastures large holdings & 33.2 & 31.1 \\
Mountain areas & 23.1 & 21.2 \\
\hline TOTAL & $19.9^{*}$ & $21.3^{*}$ \\
\hline
\end{tabular}

* Differences between 2005 and 2012 are significant at the 0.05 level 
Table 2. Latent class models for deprivation, 2005

\begin{tabular}{lcccccc}
\hline \multicolumn{1}{c}{ Model } & $\mathrm{L}^{2}$ & $\mathrm{Df}$ & Prob & $\mathrm{E}$ & $\Delta \% \mathrm{~L}^{2}$ & $\mathrm{BIC}$ \\
\hline Independence & 27994 & 502 & $1.6 \times 10^{-5535}$ & 0.000 & 0.0000 & 22708 \\
2 classes & 5888 & 492 & $7.6 \times 10^{-910}$ & 0.073 & 0.7897 & 707 \\
3 classes & 4130 & 482 & $1.7 \times 10^{-570}$ & 0.141 & 0.8525 & -945 \\
4 classes & 3526 & 472 & $4.1 \times 10^{-460}$ & 0.204 & 0.8741 & -1444 \\
\hline
\end{tabular}


Table 3. Latent class models for deprivation, 2012

\begin{tabular}{lcccccc}
\hline \multicolumn{1}{c}{ Model } & $\mathrm{L}^{2}$ & $\mathrm{df}$ & Prob & $\mathrm{E}$ & $\Delta \% \mathrm{~L}^{2}$ & $\mathrm{BIC}$ \\
\hline Independence & 34371 & 502 & $5.2 \times 10^{-6898}$ & 0.000 & 0.0000 & 29140 \\
2 classes & 4990 & 492 & $1.6 \times 10^{-732}$ & 0.046 & 0.8548 & -137 \\
3 classes & 2910 & 482 & $3.1 \times 10^{-342}$ & 0.127 & 0.9153 & -2112 \\
4 classes & 2299 & 472 & $1.6 \times 10^{-237}$ & 0.130 & 0.9331 & -2619 \\
\hline
\end{tabular}


Table 4. Deprivation risk by area

\begin{tabular}{lcccccc} 
& \multicolumn{2}{c}{ No deprivation } & \multicolumn{2}{c}{$\begin{array}{c}\text { Moderate } \\
\text { deprivation }\end{array}$} & \multicolumn{2}{c}{$\begin{array}{c}\text { Severe } \\
\text { deprivation }\end{array}$} \\
\cline { 2 - 7 } Area & 2005 & 2012 & 2005 & 2012 & 2005 & 2012 \\
\hline Urban areas & 56.0 & 55.5 & 38.4 & 34.0 & 5.6 & 10.5 \\
Intermediate areas & 53.7 & 52.6 & 41.2 & 37.4 & 5.1 & 10.0 \\
$\begin{array}{l}\text { Arable crops and permanent pastures } \\
\text { smallholdings }\end{array}$ & 61.1 & 65.2 & 37.3 & 28.0 & 1.6 & 6.8 \\
$\begin{array}{l}\text { Arable crops and permanent pastures } \\
\text { large holdings }\end{array}$ & 46.8 & 47.4 & 47.0 & 40.5 & 6.2 & 12.1 \\
Mountain areas & 57.9 & 61.7 & 39.8 & 29.8 & 2.3 & 8.5 \\
\hline Total & 55.2 & 55.0 & 39.5 & 34.8 & 5.3 & 10.3 \\
\hline
\end{tabular}


Table 5a. Structural latent class models for deprivation, 2005

\begin{tabular}{lcccccc}
\hline \multicolumn{1}{c}{ Model } & $\mathrm{L}^{2}$ & $\mathrm{df}$ & Prob & $\mathrm{E}$ & $\Delta \% \mathrm{~L}^{2}$ & $\mathrm{BIC}$ \\
\hline Full homogeneity & 4130 & 482 & $1.7 \times 10^{-570}$ & 0.1410 & 0.0000 & -945 \\
$\begin{array}{l}\text { Unrestricted } \\
\begin{array}{l}\text { Structural } \\
\text { homogeneity }\end{array}\end{array}$ & 4229.90 & 2410 & $2.5 \times 10^{-103}$ & 0.1120 & 0,0242 & -21094.30 \\
$\begin{array}{l}\text { Partial } \\
\text { homogeneity }\end{array}$ & 5399,00 & 2518 & $2.8 \times 10^{-211}$ & 0.1600 & 0,3073 & -23835.35 \\
\hline
\end{tabular}

Table 5b. Structural latent class models for deprivation, 2012

\begin{tabular}{lcccccc}
\hline \multicolumn{1}{c}{ Model } & $\mathrm{L}^{2}$ & $\mathrm{df}$ & Prob & $\mathrm{E}$ & $\Delta \% \mathrm{~L}^{2}$ & $\mathrm{BIC}$ \\
\hline Full homogeneity & 2910 & 482 & $3.1 \times 10^{-342}$ & 0.1270 & 0.0000 & -2112 \\
Unrestricted & 3553.78 & 2410 & $1.8 \times 10^{-47}$ & 0.1088 & 0,2212 & -21508.49 \\
$\begin{array}{l}\text { Structural } \\
\text { homogeneity }\end{array}$ & 4747.07 & 2518 & $5.7 \times 10^{-140}$ & 0.1181 & 0,6313 & -21438.32 \\
$\begin{array}{l}\text { Partial } \\
\text { homogeneity }\end{array}$ & 3941.96 & 2482 & $3.9 \times 10^{-70}$ & 0.1148 & 0,3546 & -21869.05 \\
\hline
\end{tabular}


Table 6. Decomposition of differences in deprivation risk, 2005-2012

\begin{tabular}{lccc}
\hline Area & $\begin{array}{c}\text { Difference in } \\
\text { deprivation risk }\end{array}$ & $\begin{array}{c}\text { Due to differences } \\
\text { in factors }\end{array}$ & $\begin{array}{c}\text { Due to differences in } \\
\text { coefficients }\end{array}$ \\
\hline Urban areas & 0.0585 & 0.0032 & 0.0553 \\
$\begin{array}{l}\text { Intermediate areas } \\
\text { Arable crops and permanent }\end{array}$ & 0.0577 & 0.0047 & 0.0530 \\
pastures small holdings & 0.0390 & -0.0054 & 0.0474 \\
$\begin{array}{l}\text { Arable crops and permanent } \\
\text { pastures large holdings }\end{array}$ & 0.0604 & -0.0232 & 0.0836 \\
Mountain areas & 0.0655 & -0.0268 & 0.0923 \\
\hline Total & 0.0550 & 0.0018 & 0.0532 \\
\hline
\end{tabular}


Figure 1. Relationship between variables in multi-group latent class models

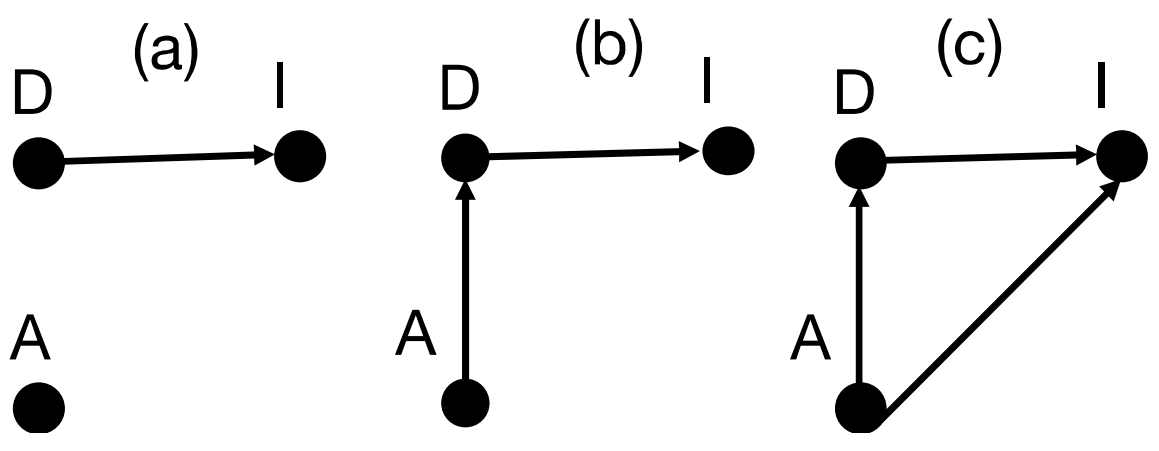


APPENDIX A

Table A1. Economic characteristics

\begin{tabular}{|c|c|c|c|c|}
\hline & \multicolumn{2}{|c|}{ Equivalent income $^{\mathrm{a}}$} & \multicolumn{2}{|c|}{ Unemployment rate } \\
\hline & 2005 & 2012 & 2005 & 2012 \\
\hline Urban areas & 12,664 & 14,907 & 11.7 & 25.6 \\
\hline Intermediate areas & 10,671 & 12,512 & 14.9 & 32.7 \\
\hline $\begin{array}{l}\text { Arable crops and permanent pastures } \\
\text { smallholdings }\end{array}$ & 9,637 & 12,270 & 14.4 & 27.2 \\
\hline $\begin{array}{l}\text { Arable crops and permanent pastures } \\
\text { large holdings }\end{array}$ & 9,120 & 10,777 & 19.7 & 35.7 \\
\hline Mountain areas & 11,169 & 13,289 & 12.8 & 26.9 \\
\hline TOTAL & 11,773 & 13,940 & 12.8 & 27.4 \\
\hline
\end{tabular}


Table A2. Demographic characteristics

\begin{tabular}{|c|c|c|c|c|c|c|c|c|c|}
\hline & \multicolumn{5}{|c|}{2005} & \multicolumn{4}{|c|}{2012} \\
\hline & 1 & 2 & 3 & 4 & 5 & 1 & 2 & 3 & 4 \\
\hline Average age & 53.3 & 53.5 & 57.0 & 55.0 & 58.0 & 53.8 & 53.9 & 57.1 & 54.6 \\
\hline \multicolumn{10}{|l|}{ Household type } \\
\hline Single person $<64$ & 3.4 & 3.3 & 2.0 & 2.8 & 2.7 & 6.2 & 5.8 & 4.5 & 4.4 \\
\hline Single person $>65$ & 3.4 & 3.7 & 5.3 & 4.1 & 4.8 & 4.2 & 4.9 & 6.9 & 4.6 \\
\hline 2 adults with no dependent children & 23.6 & 21.4 & 26.4 & 22.9 & 28.2 & 27.1 & 23.7 & 28.2 & 23.3 \\
\hline Other households with no dependent children & 26.7 & 26.8 & 25.6 & 29.7 & 25.9 & 20.8 & 21.1 & 23.7 & 21.3 \\
\hline 1 adult with 1 or more dependent children & 1.3 & 0.9 & 0.7 & 0.6 & 0.8 & 2.1 & 1.4 & 1.3 & 1.0 \\
\hline $\begin{array}{l}2 \text { adults with } 1 \text { or more dependent children } \\
\text { Other households with } 1 \text { or more dependent }\end{array}$ & 26.3 & 27.4 & 22.4 & 24.7 & 19.1 & 27.5 & 30.2 & 21.8 & 28.5 \\
\hline children & 15.2 & 16.4 & 17.4 & 15.2 & 18.5 & 12.1 & 12.9 & 13.5 & 16.8 \\
\hline \multicolumn{10}{|l|}{ Educational attainment } \\
\hline Primary education & 36.5 & 45.9 & 60.6 & 50.1 & 59.2 & 25.9 & 29.0 & 42.2 & 37.4 \\
\hline Secondary education & 36.8 & 36.1 & 28.8 & 33.8 & 27.6 & 44.7 & 49.6 & 41.3 & 42.7 \\
\hline Tertiary education & 26.6 & 18.0 & 10.6 & 16.1 & 13.2 & 29.4 & 21.4 & 16.5 & 19.9 \\
\hline \multicolumn{10}{|l|}{ Labor status } \\
\hline Working full-time & 57.5 & 52.4 & 49.5 & 47.7 & 46.8 & 44.8 & 42.0 & 39.8 & 38.5 \\
\hline Working part-time & 2.7 & 3.0 & 2.4 & 4.1 & 1.3 & 4.6 & 3.4 & 2.9 & 2.3 \\
\hline Unemployed & 4.5 & 6.6 & 4.8 & 6.3 & 5.0 & 14.0 & 17.0 & 13.3 & 20.2 \\
\hline Retired & 22.8 & 22.8 & 29.5 & 27.2 & 33.5 & 22.1 & 21.4 & 28.3 & 21.2 \\
\hline Other inactive & 12.5 & 15.3 & 13.8 & 14.7 & 13.4 & 14.6 & 16.2 & 15.7 & 17.7 \\
\hline \multicolumn{10}{|l|}{ Region } \\
\hline Galicia & 5.1 & 10.1 & 24.3 & 0.0 & 2.3 & 4.7 & 9.5 & 24.9 & 0.0 \\
\hline Asturias & 2.7 & 0.0 & 5.5 & 0.0 & 11.4 & 2.5 & 0.0 & 4.8 & 0.0 \\
\hline Cantabria & 1.5 & 0.0 & 0.0 & 1.3 & 5.8 & 1.6 & 0.0 & 0.0 & 0.8 \\
\hline País Vasco & 7.1 & 0.4 & 0.4 & 0.0 & 0.0 & 6.7 & 0.6 & 0.6 & 0.0 \\
\hline
\end{tabular}




\begin{tabular}{lcccccccccc} 
Navarra & 1.1 & 1.8 & 1.6 & 0.9 & 4.7 & 1.1 & 1.7 & 1.5 & 0.7 & 5 \\
La Rioja & 0.6 & 1.0 & 1.8 & 0.0 & 0.5 & 0.6 & 1.1 & 1.3 & 0.0 & 1 \\
Aragón & 2.6 & 2.6 & 1.1 & 6.6 & 7.9 & 2.4 & 2.7 & 1.6 & 5.4 & 1 \\
Madrid & 19.5 & 0.1 & 0.0 & 0.0 & 1.9 & 19.5 & 0.2 & 0.0 & 0.0 & 4 \\
Castilla y León & 1.4 & 11.8 & 27.4 & 7.2 & 28.5 & 1.5 & 9.7 & 26.3 & 8.1 & 2 \\
Castilla-La Mancha & 0.0 & 13.3 & 14.7 & 20.6 & 4.1 & 0.0 & 14.0 & 15.0 & 21.1 & 3 \\
Extremadura & 0.0 & 6.4 & 2.7 & 21.0 & 1.8 & 0.0 & 6.6 & 2.3 & 19.9 & 1 \\
Cataluña & 20.6 & 4.7 & 3.0 & 5.0 & 11.8 & 20.2 & 6.0 & 2.7 & 7.0 & 1 \\
C. Valenciana & 11.5 & 13.2 & 2.5 & 6.2 & 0.0 & 12.0 & 12.4 & 2.1 & 5.7 & 0 \\
Baleares & 2.8 & 1.4 & 0.0 & 0.0 & 0.0 & 3.1 & 1.0 & 0.0 & 0.0 & 0 \\
Andalucía & 14.7 & 27.5 & 10.3 & 31.2 & 12.5 & 14.7 & 28.9 & 14.4 & 31.4 & 1 \\
Murcia & 2.7 & 5.0 & 4.7 & 0.0 & 0.0 & 3.1 & 4.6 & 2.5 & 0.0 & 0 \\
Canarias & 5.7 & 0.8 & 0.0 & 0.0 & 6.9 & 5.8 & 0.9 & 0.0 & 0.0 & 7 \\
\hline Total & 100.0 & 100.0 & 100.0 & 100.0 & 100.0 & 100.0 & 100.0 & 100.0 & 100.0 & 10 \\
\hline
\end{tabular}

1:Urban areas; 2 : Intermediate areas; $3:$ Scattered rural communities; 4: Arable crops and agricultural smallholdings; $5:$ Arable crop Permanent pastures and agricultural smallholdings; 7: Permanent pastures and agricultural large holdings; 8: Mountain areas. 
Table A3. Partial deprivation indicators by area

\begin{tabular}{|c|c|c|c|c|c|c|}
\hline 2005 & $\begin{array}{l}\text { Urban } \\
\text { areas }\end{array}$ & $\begin{array}{c}\text { Other } \\
\text { intermediate } \\
\text { areas }\end{array}$ & $\begin{array}{l}\text { Arable crops } \\
\text { and } \\
\text { permanent } \\
\text { pastures } \\
\text { smallholdings }\end{array}$ & $\begin{array}{l}\text { Arable } \\
\text { crops and } \\
\text { permanent } \\
\text { pastures } \\
\text { large } \\
\text { holdings }\end{array}$ & $\begin{array}{l}\text { Mountain } \\
\text { areas }\end{array}$ & TOTAL \\
\hline Payment arrears & 7.7 & 7.5 & 4.3 & 4.4 & 3.4 & 7.1 \\
\hline Paid holidays & 40.2 & 46.4 & 44.9 & 56.3 & 43.7 & 42.5 \\
\hline $\begin{array}{l}\text { Keeping adequate } \\
\text { heating }\end{array}$ & 9.8 & 8.9 & 8.4 & 8.7 & 4.7 & 9.3 \\
\hline Unforeseen expenses & 34.6 & 34.5 & 31.6 & 39.4 & 28.6 & 34.5 \\
\hline $\begin{array}{l}\text { Eating meat or fish } \\
\text { every other day }\end{array}$ & 2.5 & 2.3 & 1.3 & 2.2 & 1.1 & 2.4 \\
\hline Having a computer & 10.7 & 15.1 & 14.1 & 20.8 & 13.3 & 12.3 \\
\hline Owning a car & 6.8 & 6.1 & 3.1 & 6.7 & 4.0 & 6.4 \\
\hline $\begin{array}{l}\text { Housing cost } \\
\text { overburden }\end{array}$ & 8.7 & 5.8 & 4.2 & 5.3 & 4.1 & 7.6 \\
\hline $\begin{array}{l}\text { Overcrowded } \\
\text { household }\end{array}$ & 9.1 & 5.9 & 6.0 & 9.9 & 7.2 & 8.4 \\
\hline 2012 & $\begin{array}{l}\text { Urban } \\
\text { areas }\end{array}$ & $\begin{array}{c}\text { Other } \\
\text { intermediate } \\
\text { areas }\end{array}$ & $\begin{array}{l}\text { Arable crops } \\
\text { and } \\
\text { permanent } \\
\text { pastures } \\
\text { smallholdings }\end{array}$ & $\begin{array}{l}\text { Arable } \\
\text { crops and } \\
\text { permanent } \\
\text { pastures } \\
\text { large } \\
\text { holdings }\end{array}$ & $\begin{array}{l}\text { Mountain } \\
\text { areas }\end{array}$ & TOTAL \\
\hline Payment arrears & 11.2 & 10.6 & 6.4 & 13.1 & 8.5 & 10.8 \\
\hline Paid holidays & 44.2 & 52.5 & 50.6 & 57.8 & 43.6 & 46.6 \\
\hline $\begin{array}{l}\text { Keeping adequate } \\
\text { heating }\end{array}$ & 8.8 & 8.8 & 10.2 & 14.0 & 7.0 & 9.2 \\
\hline Unforeseen expenses & 42.6 & 43.3 & 33.1 & 46.5 & 32.7 & 42.0 \\
\hline $\begin{array}{l}\text { Eating meat or fish } \\
\text { every other day }\end{array}$ & 2.6 & 2.3 & 1.0 & 2.6 & 4.9 & 2.6 \\
\hline Having a computer & 6.1 & 7.8 & 7.3 & 9.0 & 5.4 & 6.6 \\
\hline Owning a car & 6.6 & 4.2 & 2.3 & 4.1 & 4.2 & 5.7 \\
\hline $\begin{array}{l}\text { Housing cost } \\
\text { overburden }\end{array}$ & 15.2 & 10.8 & 7.6 & 12.0 & 10.0 & 13.7 \\
\hline $\begin{array}{l}\text { Overcrowded } \\
\text { household }\end{array}$ & 6.3 & 5.2 & 3.5 & 4.5 & 2.8 & 5.7 \\
\hline
\end{tabular}




\section{APPENDIX B}

\section{Goodness-of-Fit Testing for Latent Class Models}

Because the most appropriate model must be selected, an important question concerns the set of measures to assess the quality of the adjustment. The most common indicators are the Pearson's chi-square test and the $\mathrm{L}^{2}$ likelihood ratio, which compare the expected and observed frequencies:

$$
\begin{aligned}
\chi^{2} & =\sum_{r} \frac{\left(O_{r}-E_{r}\right)^{2}}{E_{r}} \\
L^{2} & =\sum_{r} O_{r} \ln \frac{O_{r}}{E_{r}}
\end{aligned}
$$

where $r$ is the combination of responses, $O_{r}$ the observed frequencies, and $E_{r}$ the expected frequencies. In situations in which the number of observations is very high, the model can be rejected, as shown by Hagenaars (1990). Because the sample size is very large, many small differences, when added, can lead to a very large statistic. The principle of simplicity should then guide the process of choosing the model. In this sense, ceteris paribus, a (less complex) model with fewer parameters is better than a model with more parameters (more complex). One of the most appropriate measures for implementing the principle of simplicity is the Bayesian Information Criterion $\left(\mathrm{BIC} ; \mathrm{BIC}=\mathrm{L}^{2}-\log (\mathrm{N}) \mathrm{df}\right)$, in which the effect of the sample size and the degrees of freedom are eliminated. The smaller the BIC value, the more appropriate the model will be. Another measure compares the adjustment of each model that considers a latent variable of $j$ classes with the model of independence. Therefore, the $\% L^{2}$ value indicates the degree of association explained by the latent variable:

$$
\% L^{2}=\frac{L_{0}^{2}-L_{q}^{2}}{L_{0}^{2}}
$$

\footnotetext{
i 2005 was chosen because it is the only year prior to the crisis for which the National Institute of Statistics could make the disaggregation of rural areas requested by the authors. Income data collection in the survey completely changed in 2013 and the 2012 wave was chosen for sake of comparability.

ii A two-stage design is used with first stage unit stratification. For each region, the first stage units are grouped into strata in agreement with the size of the municipality to which the section belongs. The sections are selected within each stratum with a probability proportional to their size.

iii Pereira et al. (2004) use the territorial unit called "comarca". "Comarca" is a division of territory that usually coincides with a natural area that shares physical (orography, hydrography, climate, vegetation, and soil), human (demography, economic uses, rural housing, and urban planning) and historical characteristics, all of which determine its geographical landscape. This unit is much smaller than NUTS-3 units. Therefore, there is greater homogeneity regarding productive activity, geographic, economic, and social characteristics.

iv Only one area can be assigned to each municipality, so they are mutually exclusive categories.

${ }^{\mathrm{v}}$ No other scientific study classifies the rural world in Spain using such small territorial units and so many variables related to geography, demography and economy.
} 
${ }^{\text {vi }}$ The number of observations in the survey for each area is as follows: urban areas $(20,920)$, intermediate areas $(5,726)$, arable crops and permanent pastures smallholdings $(2,313)$, arable crops and permanent pastures large holdings $(2,252)$, and mountain areas $(1,639)$. Since the survey is representative at the regional level and in more than half of the regions the sample is smaller than in the rural area with the lowest number of observations it can be expected that the defined areas are sufficiently representative.

vii In addition, tests of equality of means between the two years in these binary variables were conducted for each area considering the year as a group variable. Age, gender, size, and some types of household can be considered homogeneous according to these tests, finding in all groups -as in the country as a wholehigher educational levels in all areas in 2012.

viii A formalization of the model can be found in Pérez-Mayo (2005).

ix This structural model will be estimate twice, one for each year. The spatial areas -and not the yearsdefine the groups.

${ }^{\mathrm{x}}$ Given the randomly distribution of missing data, the gross indicators for these cases are recoded as nondeprived.

${ }^{x i}$ Housing cost overburden exists if costs exceed $40 \%$ of disposable household income without any possible housing allowances. Overcrowding happens if there are not: i) one room for the household; ii) one room per couple; iii) one room for each single person 18 years of age or older; iv) one room per pair of single people of the same gender between 12 and 17 years of age; $v$ ) one room for each single person of different gender between 12 and 17 years of age; and vi) one room per pair of children under 12 years of age.

xii Annex II provides a detailed explanation of goodness-of-Fit testing for latent class models.

xiii Since households in both waves are different, the model was estimated again in order to find the best one. Therefore, response probabilities are allowed to be different.

${ }^{\text {xiv }}$ Due to space constraints, it was not possible to include a detailed comparison of the results using national and area reference frameworks. Using national instead of area-specific references produces a higher incidence of deprivation. The results with both options are available upon request.

${ }^{\mathrm{xv}}$ These estimates are available upon request. 